\title{
Interactive Stroller for Increasing Focus Time and Participation in Learning Al Quran for Autistic Children
}

\author{
Banire Bilikis ${ }^{1,}$, Nazean Jomhari ${ }^{1, b}$ \\ ${ }^{1}$ Department of Software Engineering, Faculty of Computer Science \& Information Technology \\ University of Malaya, P.O .Box 50603, Kuala Lumpur, Malaysia \\ abanire.bilikis.o@gmail.com, ${ }^{\mathrm{b}}$ nazean@gmail.com
}

Keywords: Autism, Stroller, Prompts, Listening skills, Participation, Attention, stimulating environment.

\begin{abstract}
Autistic children possess the hyperactive type of behavior, therefore they have challenges in learning Al Quran and other academic skills due to their inability to focus and participate in learning. They exhibit minimal time of attention while learning as they enjoy sensory seeking behavior and engaging in stimulating acts such as jumping and running. Identifying suitable environment that accommodates learning and hyperactive behavior of autistic children was the aim of this study. Participant used two different learning environments; first environment was the school center where the students sit on the floor and the second environment was in a stroller. A driving car severed as the initial a learning environment for the intervention. The result indicated that the level of participation in a stroller and car increased and it was effective for gaining the child's participation compared to the traditional style.
\end{abstract}

\section{Introduction}

People with autism were identified many decades ago as people with strange behaviors to sensory stimuli. However, the degree of reactions to stimuli vary from one child to another and some usually outgrow these behaviors [1]. Autism is one of the Autism Spectrum Disorder with other disorders such as Pervasive Developmental Disorder Not Otherwise Specified (PDD NOS) and Asperger Syndrome. People with these disorders are characterized with three common impairments in the aspect of communication, responding to social gestures and stereotypical behavior. The severity of these deficits ranges from one person to another [2], where impacting academic and cognitive skills in them becomes difficult. Hence, they require life-long support for their needs either from parents or care givers. Teaching autistic children has been challenging because of their sensory and motor difficulties which makes it difficult for them to participate and engage in learning [3].

Some computer based technology interventions provided as a support for facilitating learning for autistic children has been identified as a promising intervention [4]but this intervention did not support the learning of children who has high demand for sensory stimuli because the learning environment they are provided with, did not provide needed stimuli. The ideal class environment which works for typical children will not work for the autistic children because of their sensory imbalance [5]. They require an environment that can stimulate them at the same time accommodate learning which will in turn enhance their readiness for participation and engagement [6]. However, incorporating mobility in learning could assist learner's participation [7]. An interactive stroller was proposed by this study which provides a learning and sensory stimulating environment as a therapy for hyperactive children to enhance readiness and participation in learning. A moving car served as 
the initial learning environment that provides the required stimuli . The idea of interactive stroller is to restrain sit out in learning and provide movement which stimulates their sensory needs.

\section{Methods}

Participant The participant used was Afiz who is 11 years old and diagnosed on lowfunctioning autism at the age of 3years. Afiz is hyperactive and does not sit or concentrates on a task but has a good listening skill such that he parrots whatever he hears after some minute, hours or days, sensitive to smell and likes to press on hard surfaces like keyboard and piano but dislikes body contact. Afiz lacks eye contact, turns his eyeballs to the corner side of the eye socket when he is trying to focus at times. He lacks social interaction and plays with adults only when initiated.

Afiz is hyperactive and aggressive such that he uses his fingernails to attack people around him during interaction. It has been challenging for his parents to manage him due to his behavior along with his younger brother who is also an autistic but of high function group. His mother brought him to "Akademi Fakih Center" (AFC) on March 2012 with bruises on her arms which she has sustained from him. AFC an Islamic school for people with special needs. It operates once in a week but has introduced daily classes from March 2013. He attends National Autism Society of Malaysia (NASOM). This school provides autistic children with early intervention programs. Afiz has been in the school for some time now and he could not be transferred to mainstream school due to the inability to sit and focus on the learning task. The AFC trainers found it difficult to handle Afiz for few months due to his attacking behavior. He always hits people and the environment being a new place for him he sits at the corner of the room and will not participate in any learning activity even when efforts were made by the trainers in reciting some chapters from the Quran and the Arabic alphabets.

Setting: The autistic children and other children with special needs use the same room but different sections so as to facilitate social interaction among them. Each student was assigned to one or two teachers while four people took care of the autistic child under study. Two people were engaging him in learning task, one of the volunteers took the video recording of the procedure and the other took the data of his participation, focus time and behavior while learning. The intervention has been on for a year now; data was collected for a period of two months. For each session, the maximum time used was two hours.

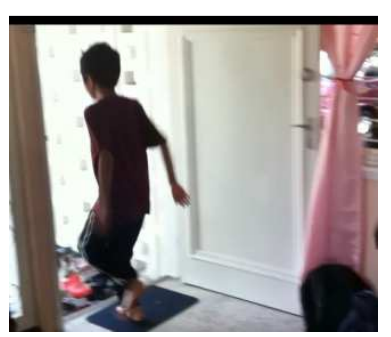

Fig.1. Afiz running out of the learning center

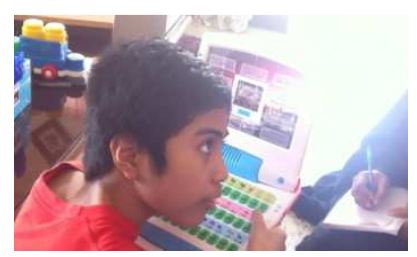

Fig.2. Afiz Listening to Quran Recitation 
Design: Therapy ball used for autistic children for gaining their attention in learning task in previous intervention yielded a positive effect [4]. Other stimulating environment could serve as a learning environment such as swing and seesaws. However, stimulating environment works differently for people with autism and hyperactivity. Therapy ball could keep some children calm while learning but Afiz requires stimulating environment that restrict his movement and at the same time accommodates his sensory needs. This restricting effect makes him adapt and accept new learning environment because he finds the new environment strange such that it takes him time to accept and adapt to such environment as shown in Fig.3. Thus, we provided him a learning environment in the car with the audiovisual player as a testing phase and we provide a moving stroller as a learning environment for the intervention. These environments stimulated him and facilitated his participation in learning, we measured this by taking his responses to the teacher's prompts and he displayed a good learning attitude as shown in Fig. 4 and Fig. 5.

Procedure According to the inquiries made from Afiz's teacher, he does not participate in reciting the chapters of the Quran he has learnt but rather runs around and outside the center. This study decided to compare the existing environment he learns from to another environment which can accommodate learning and his hyperactive behavior. There is usually a good and effective result from focusing on the strength of the autistic children which seems atypical to normal people as a medium of educating and improving their cognitive skills.

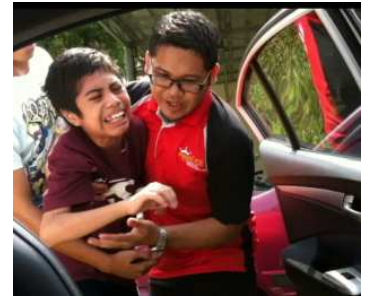

Fig.3. Getting Afiz into the Car

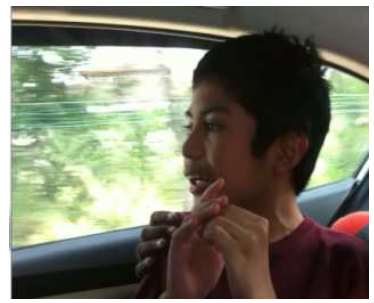

Fig.4. Afiz's participation in the car.

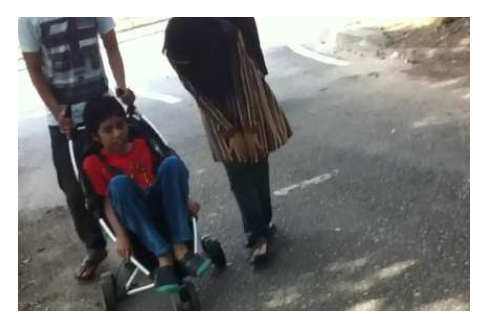

Fig.5. Afiz's participation on a stroller.

\section{Data Collection}

During the intervention, participation in learning task was measured while the duration of time he was in the seat for the learning session was observed. The intervention consists of two phases; the first phase was conducted in a room with other students. He was engaged with an audio Quran laptop toy and audio visual portable DVD. The duration of time he spent in that session was recorded and his responses to prompts on chapters of the Quran he had listened to previously were scored. In the other phase, the session was conducted in a car and the stroller that were in motion. The same variables taken in the first phase were also taken here. The duration of data collection lasted two hours for all the sessions but there was an interval of 20 minutes break for the autistic student and the teacher.

Measurement The measurement used in this study was rating scale of verbal label which is mostly used and it is a measurement instrument with more validity [4]. This study has chosen Stone and Schkade (1991) verbal label type of scale for measuring participation of the student because it has a wide range of labels. He has represented 1 for "very poor", 23 for "poor", 48 for "fair", 73 for 
"good" and 99 for "excellent". A score was assigned to the number of responses from the participant divided by the total number of prompts from the teacher multiplied by 100 in order to measure his level of participation. A total of 5 different scores was generated for each session and the average of the score for each session was used in the rating scale. Based on the verbal label rating scale used in this study, the values for the ratings were represented as: 0 for "very poor", 1 for "poor", 2 for "fair", 3 for "good" and 4 for "excellent" as depicted in Fig 6.

\section{Result}

Participation in Learning Task The result of the intervention is shown in Fig 1.0. The result indicated that the participation in the learning task of the autistic child; Afiz improved as compared to the participation in the traditional learning environment.

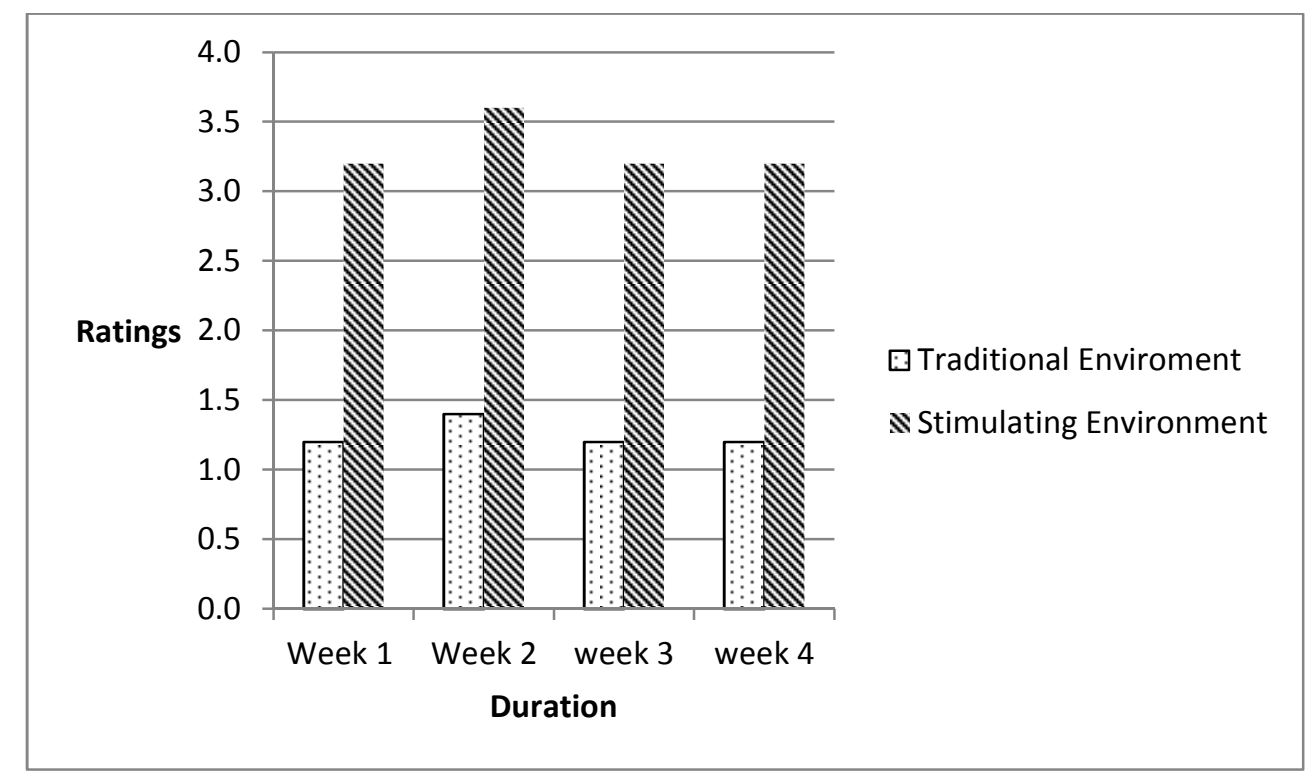

Fig. 6: Level of participation of autistic child in learning environment

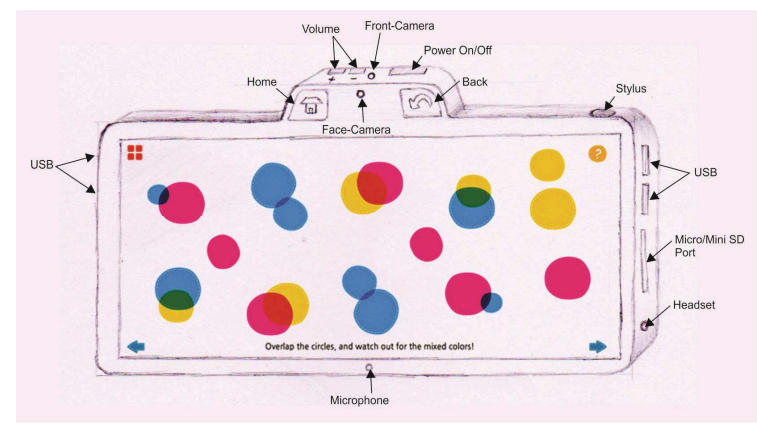

Fig. 7: Front view of the interactive device

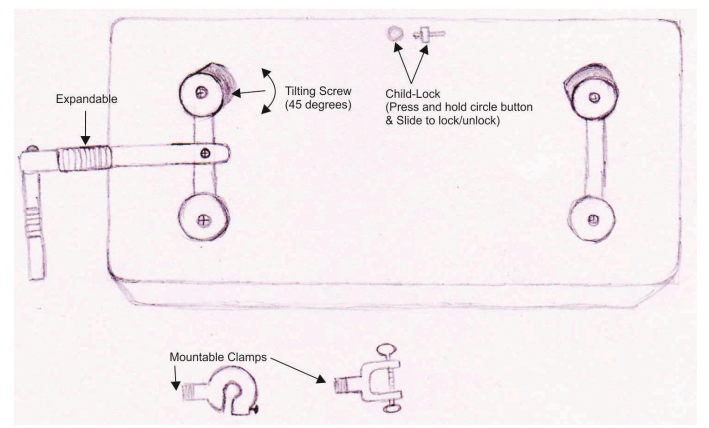

Fig. 8: Mountable clamps 


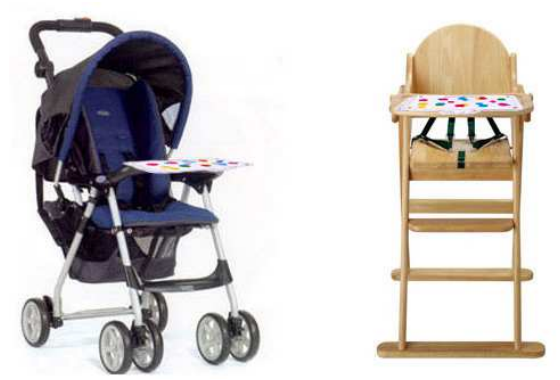

Fig. 9: How the interactive design can be mounted

\section{Discussion}

The result of the study has shown that Afiz's participation while learning and duration of time for the in seat behavior improved during a learning session in the moving car and the moving stroller than when he was in the classroom either alone or with other children. Although, while he was in class he was engaged with the pressing of the keypad of the Quran laptop toy and listening to its audio but will not respond to the teacher's prompts. These prompts were the verses from the Quran and supplications he had listened to from the toy. The essence of the participation is to ensure he has learnt the task properly. In addition, the essence of the in seat behavior is to enable him to learn more and we avoided engaging him for long duration of time as this will bore him. The findings show that Afiz was able to participate and be in seat for an average time of 20 minutes as compared to the time in class which was less than 3 minutes.

Based on our findings, the study has combined all these features to come out with a single interactive system; which is a Mountable Interactive Display Unit. The device can be designed in a way which enables the user to mount it on almost anything. It can be mounted on a table, wheelchair, chair or a stroller to name a few. The stroller will have some features such as; speaker or headsets could be mounted in order for the child to hear Quran or any other educational audio provided and a feature to lock the stroller depending on a given time.

A follow up was done for at least three weeks. The father appreciated and agreed with the approach. "I play the Quran for him in the car while coming to the center and he recites the verses of the Quran that he had listened which has not been taught by the teachers in the center".

\section{Limitation}

The limitation of this study is that it was only implemented with one participant. Thus, this intervention cannot be generalized in hyperactive children. The research will suggest that this intervention is implemented with a number of children with hyperactive behavior for future study.

\section{Conclusion}

This study has been able to identify that incorporating stroller to enhance mobility during learning for an autistic child with hyperactive behavior will increase the level of his/her participation in learning as well as having control over his movement. The use of the car can also be used as an alternative for children who must have outgrown the use of a stroller. 


\section{Acknowledgement}

We thank Nadra K. for assisting with the learning history of Afiz and her assistance during data collection. Special thanks to my colleagues Nazim A., Feisal R., and Siva B. for their assistance in the data collection and suggestions.

\section{References}

[1] L. Kanner, Autistic disturbances of affective contact, Nervous child, 2 (1943) 217-250.

[2] L. Wing, J. Gould, Severe impairments of social interaction and associated abnormalities in children: epidemiology and classification, J. Autism Dev. Disord., 9 (1979) 11-29.

[3] G.T. Baranek, Efficacy of sensory and motor interventions for children with autism, J. Autism Dev. Disord., 32 (2002) 397-422.

[4] L.E. Lyberg, P. Biemer, M. Collins, E.D. De Leeuw, C. Dippo, N. Schwarz, D. Trewin, Survey measurement and process quality, Wiley. com, 2012. 